\title{
Abomasal infusion of an exogenous emulsifier improves fatty acid digestibility and milk fat yield of lactating dairy cows
}

\author{
J. de Souza, ${ }^{*}$ M. Westerrn, $\dagger$ and A. L. Lock $\ddagger$ \\ Department of Animal Science, Michigan State University, East Lansing 48824
}

\begin{abstract}
The objective of our study was to determine the effects of abomasal infusion of an emulsifier on fatty acid (FA) digestibility and production responses of lactating dairy cows. Eight rumen-cannulated cows (109 \pm $18 \mathrm{~d}$ in milk) were randomly assigned to a treatment sequence in replicated $4 \times 4$ Latin squares with $18-\mathrm{d}$ periods including $7 \mathrm{~d}$ of washout and $11 \mathrm{~d}$ of infusion with sampling on the last $4 \mathrm{~d}$. Treatments were abomasal infusions of water carrier only $(\mathrm{CON})$ and 3 levels of increasing doses of Tween 80 (polysorbate 80, Tween 80, Sigma-Aldrich, St. Louis, MO) delivering 15 (D-15), 30 (D-30), and 45 (D-45) g/d. The Tween 80 was dissolved in water before infusions, which were delivered at 6 -h intervals. Cows were fed the same diet, which contained (\% dry matter) $31 \%$ neutral detergent fiber, $17 \%$ crude protein, $25 \%$ starch, and $4 \%$ FA (2\% dry matter from a saturated fat supplement containing $33 \%$ C16:0 and 51\% C18:0). Increasing emulsifier infusion dose quadratically increased digestibility of total FA (60.7, 65.3, 70.9, and 66.8\%), 16-carbon FA (61.7, 63.9, 70.4 , and $66.7 \%$ ), and 18-carbon FA $(59.8,65.6,71.1$, and $66.6 \%$, respectively). Increasing emulsifier infusion dose quadratically increased absorbed total FA (625, 670, 744, and $658 \mathrm{~g} / \mathrm{d}), 16$-carbon FA (151, 157, 197, and $157 \mathrm{~g} / \mathrm{d}$, quadratic), and 18-carbon FA (420, 460, 500 , and $444 \mathrm{~g} / \mathrm{d}$ ). Increasing emulsifier infusion dose tended to quadratically decrease dry matter intake $(29.0,28.8,29.6$, and $27.6 \mathrm{~kg} / \mathrm{d})$. Increasing emulsifier infusion dose quadratically increased milk fat content $(3.23,3.35,3.45$, and $3.35 \%)$, milk fat yield $(1.54,1.61$, 1.65 , and $1.55 \mathrm{~kg} / \mathrm{d})$, ECM $(45.7,46.9,47.5$, and 45.3 $\mathrm{kg} / \mathrm{d}$ ), and plasma nonesterified fatty acid concentra-
\end{abstract}

Received January 21, 2020.

Accepted February 27, 2020.

*Current address: Perdue Agribusiness, Salisbury, MD 21804.

†Current address: Vita Plus Corporation, Madison, WI 53725.

†Corresponding author: allock@msu.edu tion $(95.6,98.4,101.2$, and $98.6 \mu \mathrm{Eq} / \mathrm{L})$. On a yield basis, we observed that de novo, mixed, and preformed FA responded quadratically to Tween 80 infusion due to FA yield increasing up to D-30. Treatments had no effect on milk yield $(47.9,48.3,48.0$, and $46.6 \mathrm{~kg} / \mathrm{d})$. In conclusion, short-term infusion of an exogenous emulsifier improved FA digestibility and milk fat yield responses when cows were fed a diet containing a saturated fat supplement. Most digestion and production measurements responded quadratically because the highest dose of exogenous emulsifier $(45 \mathrm{~g} / \mathrm{d})$ decreased dry matter intake and performance.

Key words: exogenous emulsifier, fatty acid digestibility, milk fat, dairy cow

\section{INTRODUCTION}

Recently, digestion and metabolism of fatty acids (FA) in ruminants have gained interest for several reasons. Dietary FA supplements have been used to increase the energy density of rations, and therefore determining the digestibility value of different supplements is important to establish their energy value (Weiss et al., 2011; de Souza et al., 2019). Additionally, basal diets can vary dramatically in FA profile and content influencing FA digestion and metabolism even when no supplemental fat is included in diets (Rico et al., 2017; de Souza et al., 2018). Furthermore, increased recognition of the bioactive properties of specific FA has led to increased interest in the supplementation of specific FA in ruminant diets.

Regarding FA digestibility, a recent meta-analysis indicated important differences on digestibility of different FA as their intake increases (Boerman et al., 2015). Among SFA, no reduction in FA digestibility occurred when the duodenal flow of palmitic acid (C16:0) increased up to $500 \mathrm{~g} / \mathrm{d}$, whereas increasing the duodenal flow of stearic acid (C18:0) up to $500 \mathrm{~g} / \mathrm{d}$ reduced FA digestibility (Boerman et al., 2015). Similarly, 2 recent dose-response studies evaluated feeding highly enriched FA supplements containing either C16:0 (Rico et al., 2017) or C18:0 (Boerman et al., 2017) to dairy cows 
and reported that the decrease in total FA digestibility was 3 times more pronounced when there was increased intake of $\mathrm{C} 18: 0$ rather than $\mathrm{C} 16: 0$. Altogether, these studies indicate potential differences in FA digestibility that may influence energy intake and production responses. Therefore, understanding what factors limit FA digestibility is of particular importance.

Typically, FA digestibility decreases as the intake and flow of FA increases (Boerman et al., 2015). Although the exact mechanisms for the reduction in FA digestibility are not understood, potential causes include limits in lysolecithin/emulsification or competition for absorption sites (Drackley, 2000). Limitation in emulsification in the intestine is likely one of the causes for reductions in FA digestibility as the flow of FA to the intestine increases; before FA absorption can occur, it is necessary for the lipid material adsorbed onto feed particles to be solubilized into the aqueous environment. In ruminants, micelle formation is key to this process and, therefore, key to efficient FA absorption (Bauchart, 1993). Lysolecithin acts as an amphiphile for FA, increasing solubility of SFA that is required for absorption (Freeman, 1969). Also, amphiphilic compounds have the ability to expand micelle size and the hydrophobic interior, which would allow for greater incorporation of FA into the micelle, increasing FA digestibility. Although to our knowledge no reports are available in the literature evaluating the effect of exogenous emulsifiers on FA digestibility of dairy cows, it is possible to postulate that surfactant compounds may improve the digestibility of FA if emulsification in the small intestine is a limiting step to absorption.

Polysorbate 80 (Tween 80) is a nonionic surfactant with large commercial application. Although emulsifiers are commonly used in the dairy industry especially in calf milk replacers, limited research is available on using them to enhance digestion. Previous in vitro studies have reported that Tween 80 increases cellulase activity and stability (McAllister et al., 2000; Lee et al., 2003), microbial growth rates (Lee et al., 2003), and promote the binding of enzymes to their substrates and enhance microbial protease and cellulase activities (Kamande et al., 2000). Although it has been suggested that Tween 80 can increase fiber digestion, the effects of this surfactant postruminally on FA digestibility has not been evaluated. Therefore, the objective of our study was to determine the effects of abomasal infusion of Tween 80 on FA digestibility and production responses of lactating dairy cows. Based on the assumption that emulsification in the intestine is a limiting step to FA digestion, we hypothesize that Tween 80 would improve FA digestibility in diets supplemented with SFA, leading to an improvement in dairy cow performance.

\section{MATERIALS AND METHODS}

\section{Design and Treatments}

All experimental procedures were approved by the Institutional Animal Care and Use Committee at Michigan State University, East Lansing. Eight ruminally cannulated mid-lactation Holstein cows at the Michigan State University Dairy Field Laboratory were blocked by milk production and randomly assigned to a treatment sequence in replicated $4 \times 4$ Latin squares with 18-d periods. All animals received a common diet containing no supplemental fat during a 14-d preliminary period to obtain baseline values for response variables. At the beginning of the trial, mean DIM, BW, milk yield, and 3.5\% FCM (mean \pm SD) were $109 \pm 18$ $\mathrm{d}, 705 \pm 32 \mathrm{~kg}, 52.2 \pm 6.9 \mathrm{~kg} / \mathrm{d}$, and $51.3 \pm 5.9 \mathrm{~kg} / \mathrm{d}$, respectively.

Before the first treatment period, all cows were fitted with an abomasal infusion lines that were flushed daily with water to ensure proper delivery of the infusate into the abomasum. Treatment periods lasted $18 \mathrm{~d}$ including $7 \mathrm{~d}$ of washout, $7 \mathrm{~d}$ of infusion, and $4 \mathrm{~d}$ of infusion and sampling. Treatments consisted of water carrier infusion $(\mathbf{C O N})$, and 3 levels of increasing doses of Tween 80 (Sigma-Aldrich, St. Louis, MO) infused abomasally to deliver 15 (D-15), 30 (D-30), and 45 (D-45) g/d. The Tween 80 was dissolved in water before infusion and all cows received the same amount of infusate daily $(200 \mathrm{~mL})$. Treatments were infused into the abomasum via a $0.5 \mathrm{~cm}$ (i.d.) polyvinyl chloride tubing that passed through the rumen fistula and sulcus omasi (Lock et al., 2007). Solutions were prepared fresh daily and equal proportions infused every $6 \mathrm{~h}$.

For the duration of the experiment, cows consumed a common diet that contained a SFA supplement fed as a TMR. Chemical composition of Tween 80 and the fat supplement is presented in Table 1 . The diet was formulated to meet the requirements of the average cow in the group (NRC, 2001; Table 2). The DM concentration was determined twice weekly for forages and diets were adjusted when necessary. Cows were housed in tiestalls throughout the entire experiment and milked twice daily (0400 and $1500 \mathrm{~h})$. Access to feed was blocked from 0800 to $1000 \mathrm{~h}$ for collection of orts and offering of new feed. Cows were fed $115 \%$ of expected intake at $1000 \mathrm{~h}$ daily. Water was available ad libitum in each stall and stalls were bedded with sawdust and cleaned twice daily.

\section{Data and Sample Collection}

Samples and data for digestibility and production results were collected during the last $4 \mathrm{~d}$ of each treat- 
Table 1. Fatty acid (FA) profile of Tween 80 and fat supplement fed during treatment periods

\begin{tabular}{lcc}
\hline Item & Tween $80^{1}$ & Fat supplement $^{2}$ \\
\hline Selected individual FA, & & \\
g/100 g of FA & & \\
C14:0 & 2.49 & 2.64 \\
C16:0 & 4.96 & 32.8 \\
cis-9 C16:1 & 5.80 & 0.35 \\
C18:0 & 2.54 & 51.5 \\
trans C18:1 & 5.09 & 1.95 \\
trans-6 to -8 C18:1 & 0.40 & - \\
trans-9 C18:1 & 0.68 & - \\
trans-10 C18:1 & 2.97 & - \\
trans-11 C18:1 & 1.04 & 5.80 \\
cis-9 C18:1 & 66.5 & 0.34 \\
cis-11 C18:1 & 3.20 & 0.83 \\
cis-9, cis-12 C18:2 & 0.28 & - \\
cis-9, trans-11 C18:2 & 0.06 & - \\
trans-10, cis-12 C18:2 & 3.10 & 3.79 \\
Other FA & 5.98 & 90.1 \\
\hline Total FA, \% of DM & 25.1 & \\
\hline
\end{tabular}

${ }^{1}$ Tween 80 (polysorbate 80, CAS: 9005-65-6, Sigma-Aldrich, St. Louis, $\mathrm{MO})$.

${ }^{2}$ Fat supplement (Energy Booster 100, Milk Specialties Global, Eden Prairie, MN).

ment period (d 15 to 18). Samples of all diet ingredients $(0.5 \mathrm{~kg})$ and orts from each cow $(12.5 \%)$ were collected daily and composited by period for analysis. Milk yield was recorded and 2 milk samples were collected at each milking. One aliquot was collected in a sealed tube with preservative (bronopol tablet; D\&F Control Systems, San Ramon, CA) and stored at $4^{\circ} \mathrm{C}$ for milk component analysis. The second aliquot was stored without preservative at $-20^{\circ} \mathrm{C}$ until it could be analyzed for FA composition.

Fecal ( 400 g) and blood $(\sim 15 \mathrm{~mL})$ samples were collected every $9 \mathrm{~h}$ during the last $4 \mathrm{~d}$ of each period resulting in 8 samples per cow per period, representing every $3 \mathrm{~h}$ of a 24 -h period to account for diurnal variation. Feces were stored at $-20^{\circ} \mathrm{C}$ until samples were dried and composited on equal DM basis for each cow period. Cows were weighed on the last $2 \mathrm{~d}$ of each period and 3 trained investigators determined BCS on a 5 -point scale in 0.25 increments on the last day of each period (Wildman et al., 1982).

\section{Sample Analysis}

Diet ingredients, orts, and fecal samples were dried at $55^{\circ} \mathrm{C}$ in a forced-air oven for $72 \mathrm{~h}$ for $\mathrm{DM}$ determination. Dried samples were ground with a Wiley mill (1-mm screen, Arthur H. Thomas, Philadelphia, PA). Samples of feed ingredients, orts, and feces were analyzed for ash, NDF, indigestible NDF, CP, starch, and FA concentration as described by Boerman et al. (2017). Indigestible NDF was used as an internal marker to estimate fecal output to determine apparent total-tract digestibility of nutrients (Cochran et al., 1986). Indigestible NDF was estimated as NDF after a 240-h in vitro fermentation (Goering and Van Soest, 1970).

Individual milk samples were analyzed for fat, true protein, and lactose concentrations by mid-infrared spectroscopy (AOAC, 1990, method 972.160) by the Michigan Herd Improvement Association (Universal Lab Services, Lansing, MI). Yields of 3.5\% FCM, ECM, and milk components were calculated using milk yield and component concentrations for each milking, summed for a daily total, and averaged for each collection period. Milk samples used for analysis of FA composition were composited based on milk fat yield (d 14-18 of each period). Milk lipids were extracted and FAME prepared and analyzed according to Lock et al. (2013). Yield of individual FA in milk fat was calculated by correcting for glycerol content and other milk lipid classes according to Piantoni et al. (2013).

All plasma samples were analyzed in duplicate with a coefficient of variation of $<5 \%$ between duplicates. Commercial kits were used to determine plasma concentrations of nonesterified fatty acids (NEFA; NEFA-

Table 2. Ingredient and nutrient composition of treatment diet

\begin{tabular}{lc}
\hline Item & \% of DM \\
\hline Ingredient & \\
Corn silage & 26.7 \\
Alfalfa silage & 20.0 \\
Wheat straw & 2.60 \\
Ground corn & 12.6 \\
High-moisture corn & 12.6 \\
Soybean meal & 13.4 \\
Soyhulls & 6.88 \\
Dairy vitamin-mineral mix $^{1}$ & 3.20 \\
Fat supplement & 1.98 \\
Nutrient composition & \\
NDF & \\
Forage NDF & 31.5 \\
CP & 22.9 \\
Starch & 16.7 \\
Fatty acids & 25.0 \\
C16:0 & 3.57 \\
C18:0 & 0.85 \\
cis-9 $^{2}$ Cis-12 C18:2 & 0.99 \\
cis-9, $^{2}$ (is-12, cis-15 C18:3 & 0.43 \\
Other fatty acids & 0.85 \\
\hline
\end{tabular}

${ }^{1}$ Vitamin and mineral mix contained $34.1 \%$ dry ground shelled corn, $25.6 \%$ white salt, $21.8 \%$ calcium carbonate, $9.1 \%$ Biofos (The Mosaic Co., Plymouth, MN), $3.9 \%$ magnesium oxide, $2 \%$ soybean oil, and $<1 \%$ of each of the following: manganese sulfate, zinc sulfate, ferrous sulfate, copper sulfate, iodine, cobalt carbonate, vitamin E, vitamin A, vitamin $\mathrm{D}$, and selenium.

${ }^{2}$ Fat supplement (Energy Booster 100, Milk Specialties Global, Eden Prairie, MN).

${ }^{3}$ Diet nutrient composition determined from calculations based on individual ingredient composition. 
HR kit, Wako Chemicals, Richmond, VA). Insulin was measured with a bovine insulin ELISA using a solidphase 2-site enzyme immunoassay (Mercodia, Uppsala, Sweden). Glucose was quantified using a glucose oxidase method (PGO Enzyme Product No. P7119, Sigma Chemical Co., St. Louis, MO).

\section{Statistical Analysis}

All data were analyzed using a mixed model procedure of SAS (version 9.4, SAS Institute Inc., Cary, NC). Data were analyzed using the following model:

$$
\mathrm{Y}_{\mathrm{ijk}}=\mu+\mathrm{C}(\mathrm{S})_{\mathrm{i}(\mathrm{j})}+\mathrm{S}_{\mathrm{j}}+\mathrm{P}_{\mathrm{k}}+\mathrm{T}_{1}+\mathrm{e}_{\mathrm{ijkl}},
$$

where $\mathrm{Y}_{\mathrm{ijk}}=$ the dependent variable, $\mu=$ the overall mean, $\mathrm{C}(\mathrm{S})_{\mathrm{i}(\mathrm{j})}=$ random effect of cow nested within square $(\mathrm{i}=1$ to 4$), \mathrm{S}_{\mathrm{j}}=$ the fixed effect of square $(\mathrm{j}=$ 1 to 2$), P_{k}=$ the fixed effect of period ( $\mathrm{k}=1$ to 4$), \mathrm{T}_{1}$ $=$ the fixed effect of treatment $(\mathrm{l}=1$ to 4$)$, and $\mathrm{e}_{\mathrm{ijkl}}=$ the residual error. The interactions between period and treatment, period and square, and square and treatments were initially included in the model and removed because they were not significant (all $P>0.20$ ). Three preplanned contrasts were used to determine the linear, quadratic, and cubic effects of increasing doses of Tween 80. Cubic effects were initially included in the model and removed because they were not significant (all $P>0.20$ ). Treatment terms were declared significant at $P \leq 0.05$ and trends were declared at $P \leq 0.10$. To evaluate the relationship between FA intake and FA output in the feces, a linear regression analysis was performed for each treatment using the REG procedure of SAS (version 9.4, SAS Institute Inc.).

\section{RESULTS}

\section{Infusate, Diets, and Nutrient Composition}

The composition of Tween 80 and the dietary fat supplement is presented at Table 1 . The cis-9 C18:1 was the main FA in Tween 80, resulting in the delivery of $2.4,4.8$, and $7.2 \mathrm{~g} / \mathrm{d}$ of cis-9 C18:1 for D-15, D-30, and D-45, respectively. The fat supplement used in our study was a mostly saturated prilled fat and the main FA were C18:0 and C16:0. Cows received the same diet containing $25.0 \%$ starch, $31.5 \% \mathrm{NDF}$, and $3.60 \%$ total FA (Table 2).

\section{Total-Tract Digestibility}

Increasing emulsifier infusion dose tended to quadratically decrease DMI $(P=0.09$; Table 3$)$. Although DM digestibility was not affected by treatments, NDF digestibility tended to reduce (quadratic $P=0.08$ ) with increasing Tween 80 dose. Intake of 18-carbon, and total FA increased with increasing Tween 80 up to D-30 and reduced at D-45 (quadratic $P<0.05$ ). Increasing Tween 80 infusion quadratically increased 18 -carbon $(P$ $=0.04)$ and total FA digestibility $(P=0.05)$ due to FA digestibility increasing up to D-30. We observed a similar tendency for 16-carbon FA digestibility $(P=0.10)$. Also, based on the regression intercepts and slopes generated, increasing FA intake linearly increased the amount of FA in feces, but the increase was at a lower extent as Tween 80 dose increased (Figure 1). Increasing Tween 80 increased absorbed total FA (quadratic, $P=0.01$ ), which was most evident for 18-carbon FA with absorbed FA increasing by $\sim 90 \mathrm{~g}$ (quadratic, $P$ $=0.01$ ) when comparing CON versus D-30. Total FA intake increased $\sim 21 \mathrm{~g}$ and total absorbed FA increased $\sim 119 \mathrm{~g}$ when comparing CON versus D-30. Absorbed 16-carbon FA was increased by $\sim 36 \mathrm{~g}$ (quadratic, $P=$ 0.04) when comparing CON versus D-30.

\section{Production Responses and Blood Metabolites}

Increasing Tween 80 infusion quadratically affected milk fat content $(P=0.03$; Table 4$)$ and milk fat yield $(P=0.02)$ mainly due to milk fat increasing up to D-30. Additionally, yields of $3.5 \%$ FCM and ECM increased up to D-30 (quadratic, both $P=0.03$ ) compared with CON. Although milk yield was not affected by treatments $(P=0.12)$, yields of milk protein and lactose tended to respond quadratically to treatments $(P<0.10)$. In our 18-d treatment periods, we observed no effect of Tween 80 on feed efficiency $(P=0.23)$ or BW change $(P=0.24)$. In contrast, we observed a tendency for a linear reduction in BW $(P=0.07)$, which occurred due to the reduction of this variable for D-45. Additionally, although glucose and insulin concentrations were not affected by treatments $(P>0.10)$, NEFA concentration responded quadratically due to it increasing up to D-30 $(P=0.05$; Table 5$)$.

\section{Milk Fatty Acid Yield and Concentration}

Milk FA are derived from 2 sources: $<16$ carbon FA from de novo synthesis in the mammary gland and $>16$ carbon FA originating from extraction from plasma. Mixed-source FA (C16:0 and cis-9 C16:1) originate from de novo synthesis in the mammary gland and extraction from plasma. On a yield basis, we observed that de novo, mixed, and preformed FA responded quadratically to Tween 80 infusion due to FA yield increasing up to D-30 $(P<0.05$; Table 6$)$. When comparing CON versus $\mathrm{D}-30$, the yield of de novo $\mathrm{FA}$ increased by $\sim 22$ $\mathrm{g}$ due to the increase in C6:0, C8:0, C12:0, and C14:0. 
Also, D-30 increased mixed FA yield $(\sim 40 \mathrm{~g})$ compared with CON due to the increase in yield of C16:0 and cis-9 C16:1. Preformed FA yield increased by $\sim 34 \mathrm{~g}$ when comparing CON versus D-30 mainly because of the increase in the yield of $\mathrm{C} 18: 0$ and cis-9 C18:1. On a concentration basis, we observed that mixed FA responded quadratically $(P=0.01)$, whereas preformed FA tended to respond quadratically $(P=0.06)$ to Tween 80 infusion (Table 7). The concentration of mixed FA increased up to D-30 and reduced at D-45, whereas the concentration of preformed FA tended to decrease at D-30 compared with other treatments. Treatments did not affect de novo FA concentration $(P=0.29)$.

\section{DISCUSSION}

Digestion and metabolism of FA in ruminants has gained interest from both a research and industry perspective due to their utilization as an energy source, and the recognition of the bioactive properties of specific FA (Boerman et al., 2015). Changes in intake and nutrient digestibility due to supplemental fat may affect, positively or negatively, digestible energy available for milk production, body reserves, or both (Boerman et al., 2015). In this regard, a better understanding of factors that influence FA digestibility are useful in developing strategies for diet formulation and provide critical information for optimal FA supplementation. It is well established that in ruminants, micelle formation is key to efficient FA absorption (Davis, 1990). We suggest that a limitation in emulsification capacity in the intestine is likely one of the causes for a reduction in
FA digestibility as the flow of FA to intestine increases, and therefore increasing the supply of emulsifiers compounds may positively influence FA digestibility and production responses. Usually UFA have higher digestibility than SFA (Boerman et al., 2015), which may be due to the greater solubility of UFA facilitating transfer of FA to micelles (Freeman, 1969), and rapid uptake and re-esterification in enterocytes compared with SFA (Ockner et al., 1972). Therefore, in our diet we supplemented a commercially available SFA (mainly C16:0 and C18:0) because of their lower solubility and absorption potentially being increased due to the supply of emulsifiers. Therefore, due to the importance of FA digestibility when evaluating fat supplements, we conducted the current experiment to determine the effect of abomasal infusion of an exogenous emulsifier on FA digestibility and production responses of lactating dairy cows.

In our recent meta-analysis evaluating the digestibility of individual FA using duodenally cannulated cows, we determined that FA digestibility consistently decreased as the intake or duodenal flow of FA increased (Boerman et al., 2015). Potential causes for this reduction in digestibility include limits in lysolecithin/emulsification or competition for absorption sites (Drackley, 2000). In ruminants both the bile and pancreatic secretions are required for FA digestion; bile supplies bile salts and lecithin, and pancreatic juice provides enzymes to convert lecithin to lysolecithin and bicarbonate to increase the pH (Bauchart, 1993; Lock et al., 2006). Lysolecithin, together with bile salts, desorb the FA from feed particles and bacteria, allowing the formation of

Table 3. Intake, total-tract digestibility, and absorbed fatty acids $(F A)$ of cows fed treatment diets $(\mathrm{n}=8)$

\begin{tabular}{|c|c|c|c|c|c|c|c|}
\hline \multirow[b]{2}{*}{ Variable } & \multicolumn{4}{|c|}{ Treatment $^{1}$} & \multirow[b]{2}{*}{ SEM } & \multicolumn{2}{|c|}{ Contrast $^{2}$} \\
\hline & $\mathrm{CON}$ & D-15 & D-30 & D-45 & & Linear & Quadratic \\
\hline \multicolumn{8}{|l|}{ Intake, kg/d } \\
\hline $\mathrm{DM}$ & 29.0 & 28.8 & 29.6 & 27.6 & 0.82 & 0.14 & 0.09 \\
\hline \multicolumn{8}{|l|}{ Intake, ${ }^{3} \mathrm{~g} / \mathrm{d}$} \\
\hline Total FA & 1,029 & 1,026 & 1,050 & 985 & 29.1 & 0.20 & 0.01 \\
\hline 16-Carbon & 245 & 245 & 251 & 235 & 6.94 & 0.22 & 0.12 \\
\hline 18-Carbon & 703 & 701 & 717 & 672 & 15.1 & 0.19 & 0.05 \\
\hline \multicolumn{8}{|c|}{ Digestibility, \% } \\
\hline DM & 66.7 & 66.2 & 65.8 & 66.6 & 0.61 & 0.64 & 0.12 \\
\hline $\mathrm{NDF}$ & 45.5 & 43.9 & 43.5 & 44.0 & 1.05 & 0.30 & 0.08 \\
\hline Total FA & 60.7 & 65.3 & 70.9 & 66.8 & 2.25 & 0.02 & 0.05 \\
\hline 16-Carbon & 61.7 & 63.9 & 70.4 & 66.7 & 1.85 & 0.02 & 0.10 \\
\hline 18-Carbon & 59.8 & 65.6 & 71.1 & 66.6 & 1.72 & 0.02 & 0.04 \\
\hline \multicolumn{8}{|l|}{ Absorbed, g/d } \\
\hline Total FA & 625 & 670 & 744 & 658 & 18.4 & 0.19 & 0.01 \\
\hline 16-Carbon & 151 & 157 & 197 & 157 & 6.61 & 0.20 & 0.04 \\
\hline 18-Carbon & 420 & 460 & 500 & 444 & 18.8 & 0.19 & 0.01 \\
\hline
\end{tabular}

${ }^{1}$ Treatments contained 0 (CON), 15 (D-15), 30 (D-30), or 45 (D-45) g/d of Tween 80 (Sigma-Aldrich, St. Louis, $\mathrm{MO})$ abomasally infused.

${ }^{2}$ Contrasts correspond to the linear and quadratic effects of increasing Tween 80 .

${ }^{3}$ The amount of FA in the infusate was considered for the intake and digestibility of FA. 
Table 4. Milk yield, milk composition, BW, and BCS of cows fed treatment diets $(\mathrm{n}=8)$

\begin{tabular}{|c|c|c|c|c|c|c|c|}
\hline \multirow[b]{2}{*}{ Variable } & \multicolumn{4}{|c|}{ Treatment $^{1}$} & \multirow[b]{2}{*}{ SEM } & \multicolumn{2}{|c|}{ Contrast $^{2}$} \\
\hline & $\mathrm{CON}$ & D-15 & D-30 & D-45 & & Linear & Quadratic \\
\hline \multicolumn{8}{|l|}{ Milk yield, $\mathrm{kg} / \mathrm{d}$} \\
\hline Milk & 47.9 & 48.3 & 48.0 & 46.6 & 1.66 & 0.15 & 0.20 \\
\hline $3.5 \% \mathrm{FCM}^{3}$ & 45.7 & 46.9 & 47.5 & 45.3 & 1.87 & 0.91 & 0.03 \\
\hline $\mathrm{ECM}^{4}$ & 45.8 & 46.9 & 47.4 & 45.1 & 1.96 & 0.64 & 0.03 \\
\hline \multicolumn{8}{|l|}{ Milk composition } \\
\hline Fat, $\mathrm{kg} / \mathrm{d}$ & 1.54 & 1.61 & 1.65 & 1.55 & 0.07 & 0.57 & 0.02 \\
\hline Fat, $\%$ & 3.23 & 3.35 & 3.45 & 3.35 & 0.09 & 0.15 & 0.03 \\
\hline Protein, $\mathrm{kg} / \mathrm{d}$ & 1.43 & 1.46 & 1.45 & 1.38 & 0.06 & 0.12 & 0.08 \\
\hline Protein, \% & 3.02 & 3.04 & 3.04 & 2.97 & 0.07 & 0.19 & 0.08 \\
\hline Lactose, $\mathrm{kg} / \mathrm{d}$ & 2.28 & 2.33 & 2.32 & 2.23 & 0.13 & 0.37 & 0.10 \\
\hline Lactose, $\%$ & 4.75 & 4.84 & 4.85 & 4.79 & 0.05 & 0.60 & 0.16 \\
\hline FCM/DMI & 1.57 & 1.63 & 1.61 & 1.65 & 0.07 & 0.19 & 0.81 \\
\hline $\mathrm{BW}, \mathrm{kg}$ & 706 & 704 & 707 & 694 & 17.2 & 0.07 & 0.19 \\
\hline BW change, $\mathrm{kg} / \mathrm{d}$ & 0.04 & 0.05 & 0.02 & -0.02 & 0.05 & 0.24 & 0.19 \\
\hline
\end{tabular}

${ }^{1}$ Treatments contained 0 (CON), 15 (D-15), 30 (D-30), or 45 (D-45) g/d of Tween 80 (Sigma-Aldrich, St. Louis, MO) abomasally infused.

${ }^{2}$ Contrasts correspond to the linear and quadratic effects of increasing Tween 80 .

${ }^{3} 3.5 \% \mathrm{FCM}=[(0.4324 \times \mathrm{kg}$ of milk $)+(16.216 \times \mathrm{kg}$ of milk fat $)]$.

${ }^{4} \mathrm{ECM}=[(0.327 \times \mathrm{kg}$ of milk $)+(12.95 \times \mathrm{kg}$ of milk fat $)+(7.20 \times \mathrm{kg}$ of milk protein $)]$.

the micelle (Moore and Christie, 1984). In our trial, we observed that FA digestibility increased $\sim 10$ percentage units when we infused up to $30 \mathrm{~g} / \mathrm{d}$ of an exogenous emulsifier. When the dose of exogenous emulsifier was increased to $45 \mathrm{~g} / \mathrm{d}$, we still observed an increase in FA digestibility of $\sim 7$ percentage units compared with control. Although data on the effects of emulsifiers on FA digestibility are limited in ruminants, Jenkins and Fotouhi (1990) reported that feeding lecithin slightly improved postrumen FA digestibility in sheep. In nonruminants, although the mechanism of FA absorption is different than ruminants, previous studies indicated

$\bullet \mathrm{CON} \square \mathrm{D}-15 \Delta \mathrm{D}-30 \diamond \mathrm{D}-45$

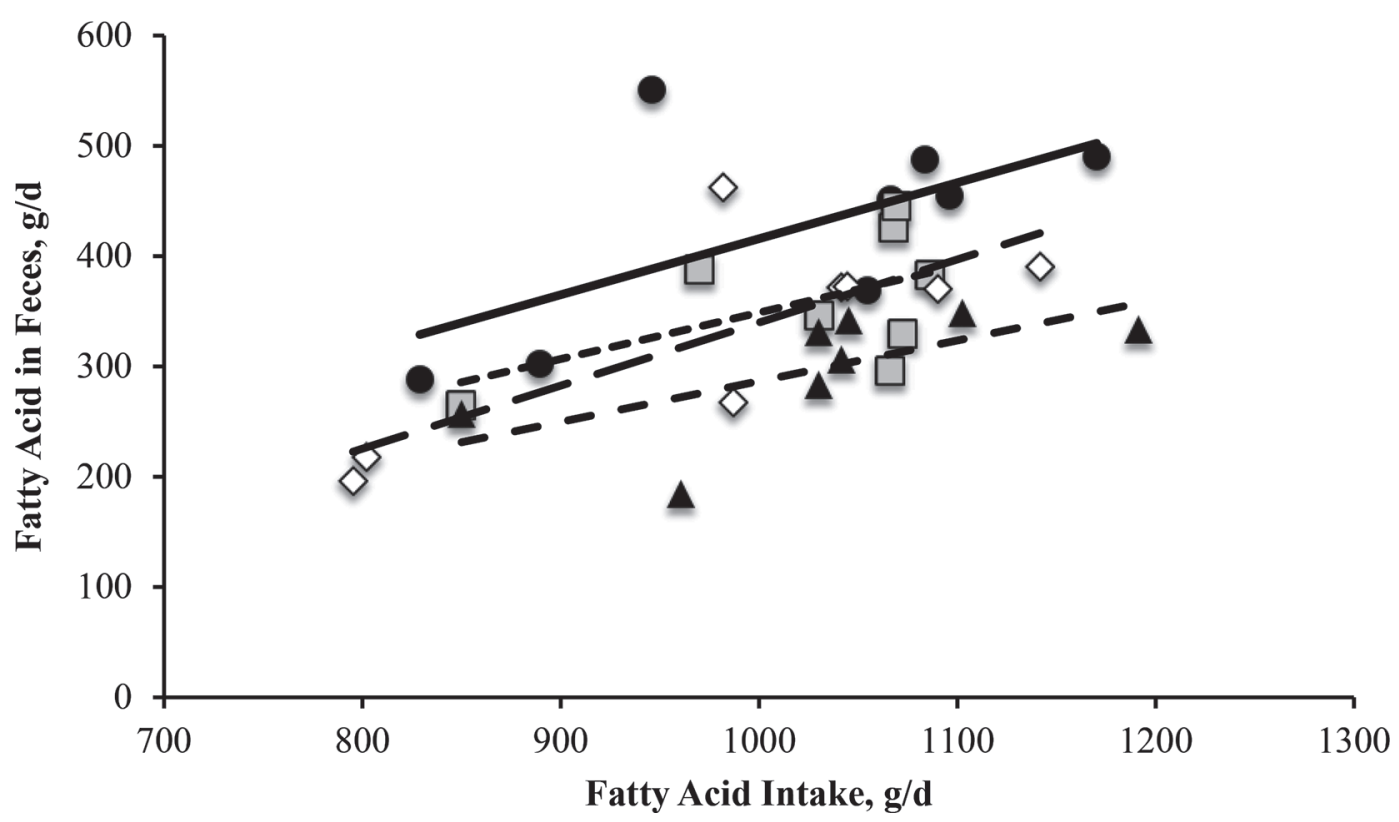

Figure 1. Relationship between fatty acid intake and fatty acid in feces of dairy cows. Treatment were (a) control (CON, solid line; Y $=92.3$ $+0.51 \mathrm{x} ; \mathrm{R}^{2}=0.40$ ); (b) $15 \mathrm{~g} / \mathrm{d}$ of Tween 80 (Sigma-Aldrich, St. Louis, MO) abomasally infused (D-15, short-dashed line; Y = 72.1 + 0.42x; $\mathrm{R}^{2}=0.35$ ); (c) $30 \mathrm{~g} / \mathrm{d}$ of Tween 80 abomasally infused (D-30, medium-dashed line; $\mathrm{Y}=82.4+0.36 \mathrm{x} ; \mathrm{R}^{2}=0.44$ ); and (d) $45 \mathrm{~g} / \mathrm{d}$ of Tween 80 abomasally infused (D-45, long-dashed line; $\left.\mathrm{Y}=85.7+0.40 \mathrm{x} ; \mathrm{R}^{2}=0.60\right)$. 
Table 5. Blood metabolites of cows fed treatment diets $(\mathrm{n}=8)$

\begin{tabular}{|c|c|c|c|c|c|c|c|}
\hline \multirow[b]{2}{*}{ Variable } & \multicolumn{4}{|c|}{ Treatment $^{1}$} & \multirow[b]{2}{*}{ SEM } & \multicolumn{2}{|c|}{ Contrast $^{2}$} \\
\hline & $\mathrm{CON}$ & D-15 & D-30 & D-45 & & Linear & Quadratic \\
\hline Glucose, mg/dL & 58.2 & 59.3 & 58.7 & 57.9 & 1.07 & 0.62 & 0.22 \\
\hline Insulin, $\mu \mathrm{g} / \mathrm{L}$ & 1.25 & 1.33 & 1.29 & 1.33 & 0.17 & 0.38 & 0.79 \\
\hline $\mathrm{NEFA}^{3}{ }^{3} \mu \mathrm{Eq} / \mathrm{L}$ & 95.6 & 98.4 & 101.2 & 98.6 & 2.45 & 0.01 & 0.05 \\
\hline
\end{tabular}

${ }^{1}$ Treatments contained 0 (CON), 15 (D-15), 30 (D-30), or 45 (D-45) g/d of Tween 80 (Sigma-Aldrich, St. Louis, $\mathrm{MO})$ abomasally infused.

${ }^{2}$ Contrasts correspond to the linear and quadratic effects of increasing Tween 80 .

${ }^{3} \mathrm{NEFA}=$ nonesterified fatty acids.

that addition of emulsifiers to diets increased fat digestibility and performance of pigs (Zhao et al., 2015) and poultry (Upadhaya et al., 2017). Although we did not directly measure micelle formation, our results agree with most of the nonruminant literature on the positive effects of supplementing emulsifiers to increase FA digestibility, which is likely associated with better emulsification capacity.

While total flow of FA at the duodenum affects FA digestibility (Boerman et al., 2015), recent studies indicate that the profile of FA entering the duodenum is also a critical factor affecting FA digestibility (i.e., Rico et al., 2017; de Souza et al., 2018). Boerman et al. (2015) reported no reduction in FA digestibility when the duodenal flow of C16:0 increased up to $500 \mathrm{~g} / \mathrm{d}$, whereas increasing the duodenal flow of C18:0 linearly reduced FA digestibility. Similarly, 2 recent dose-response studies evaluated feeding a highly enriched FA supplement containing C16:0 (Rico et al., 2017) or C18:0 (Boerman et al., 2017) to dairy cows and reported that the decrease in total FA digestibility was 3 times more pronounced when intake of C18:0 was increased rather than C16:0. Using radiolabeled FA in sheep, Harrison and Leat (1972) reported that compared with C18:0, C16:0 increased the rate of absorption and therefore the total percentage of FA absorbed. Potentially, these

Table 6. Milk fatty acid (FA) yield of cows fed treatment diets $(\mathrm{n}=8)$

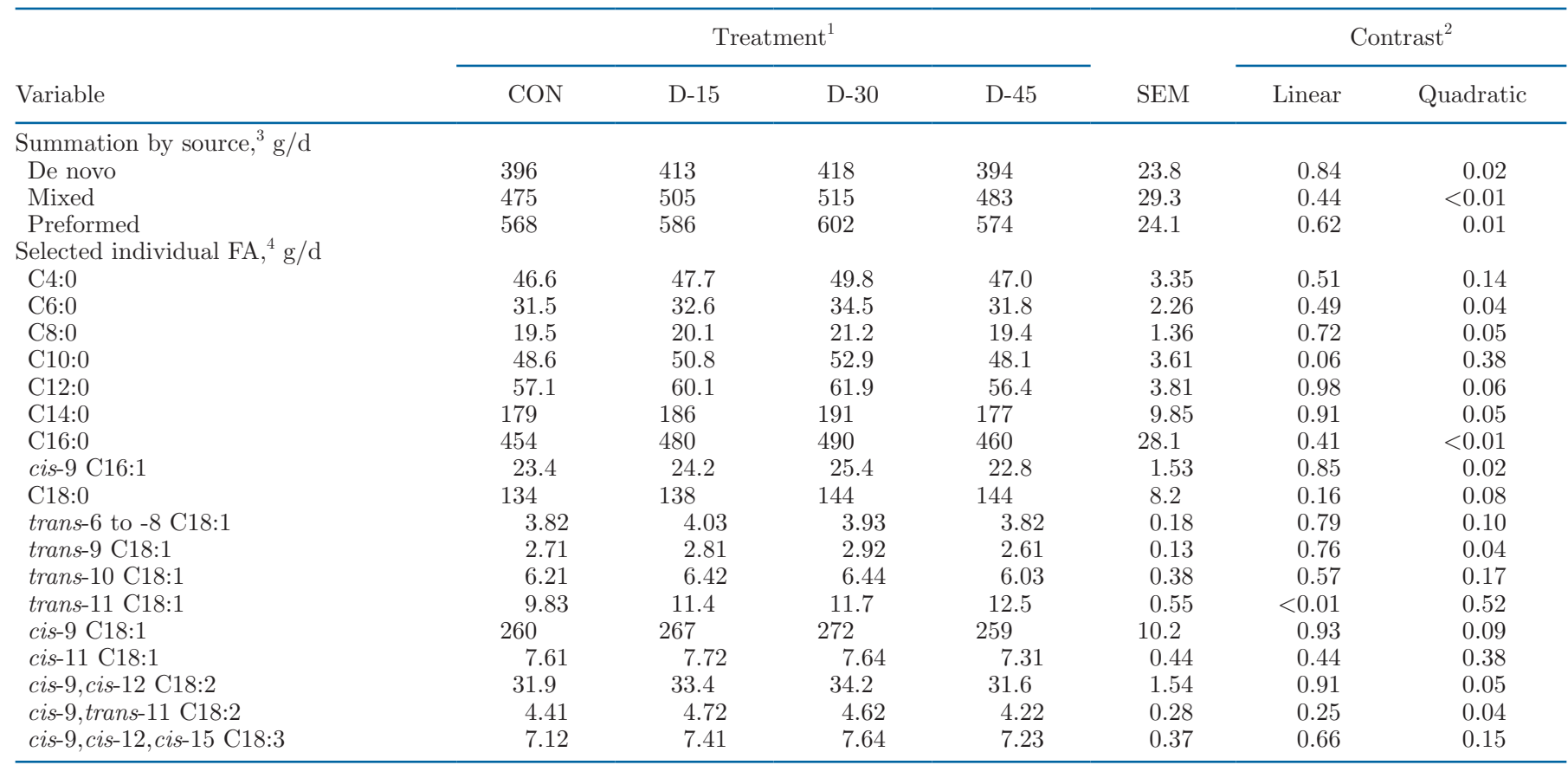

\footnotetext{
${ }^{1}$ Treatments contained 0 (CON), 15 (D-15), 30 (D-30), or 45 (D-45) g/d of Tween 80 (Sigma-Aldrich, St. Louis, MO) abomasally infused.

${ }^{2}$ Contrasts correspond to the linear and quadratic effects of increasing Tween 80 .

${ }^{3}$ De novo FA originate from mammary de novo synthesis ( $<16$ carbons), preformed FA originate from extraction from plasma ( $>16$ carbons), and mixed FA originate from both sources (C16:0 plus cis-9 C16:1).

${ }^{4} \mathrm{~A}$ total of approximately 70 individual FA were quantified and used for calculations (summation by concentrations). Only select FA are reported in the table.
} 
differences in absorption between FA that only differ in chain length are due to the increased ability of C16:0 to form micelles. Because we did not use duodenally cannulated cows in our current study, we are unable to estimate individual FA digestibility per se due to rumen biohydrogenation. Rather, utilizing feed to feces measurements, we combined all 16- and 18-carbon FA into single digestibility estimates. We observed that 16carbon FA digestibility increased $\sim 9$ percentage units when we infused up to $30 \mathrm{~g} / \mathrm{d}$ of an exogenous emulsifier. Similarly, we observed that 18-carbon FA digestibility increased $\sim 11$ percentage units when we infused up to $30 \mathrm{~g} / \mathrm{d}$ of an exogenous emulsifier. Doreau and Chilliard (1997) indicated that either micelle formation or production of biliary salts might be affected by the total amount and profile of FA reaching the intestine. In our trial, even though the intake of 18-carbon FA was $\sim 3$ times greater than the intake of 16 -carbon FA, the improvement on FA digestibility in a percentage basis due to the supply of an exogenous emulsifier was similar between these groups of FA. Therefore, we are unable to identify specifically whether all FA or specific FA are positively affected by emulsifiers to a greater extent. Further research is needed to determine possible interactions between emulsification capacity and diet FA profile.

We observed that DMI responded quadratically to exogenous emulsifier infusion due to DMI decreasing at the highest level (45 g/d). Shain et al. (1993) reported that feeding soy lecithin either to lactating cows or steers did not affect DMI compared with a control diet. Lee et al. (2019) fed 2 levels of lysophospholipids to lactating dairy cows and did not observe changes in DMI. In our study, the total FA level of the diet was slightly higher than in the studies of Shain et al. (1993) and Lee et al. (2019), but this likely did not affect feed intake. When fed at up to $3 \%$ of dietary DM, SFA supplementation mostly results in no change in DMI (Palmquist and Jenkins, 1980; Allen, 2000). Tween 80 is a widely used commercial emulsifier, but high levels may be toxic. In rats, levels of Tween 80 over $10 \%$ of the diet induced diarrhea and reduced growth (Eagle and Poling, 1956; Marszall, 1973). However, it is unlikely the highest dose used in our study induced toxicity. To our knowledge, our study is the first to abomasally infuse an exogenous emulsifier; therefore, we speculate that our observed effects on feed intake are likely related to stimulation of satiety signals in the gut. For instance, the decrease in

Table 7. Milk fatty acid (FA) concentration of cows fed treatment diets $(\mathrm{n}=8)$

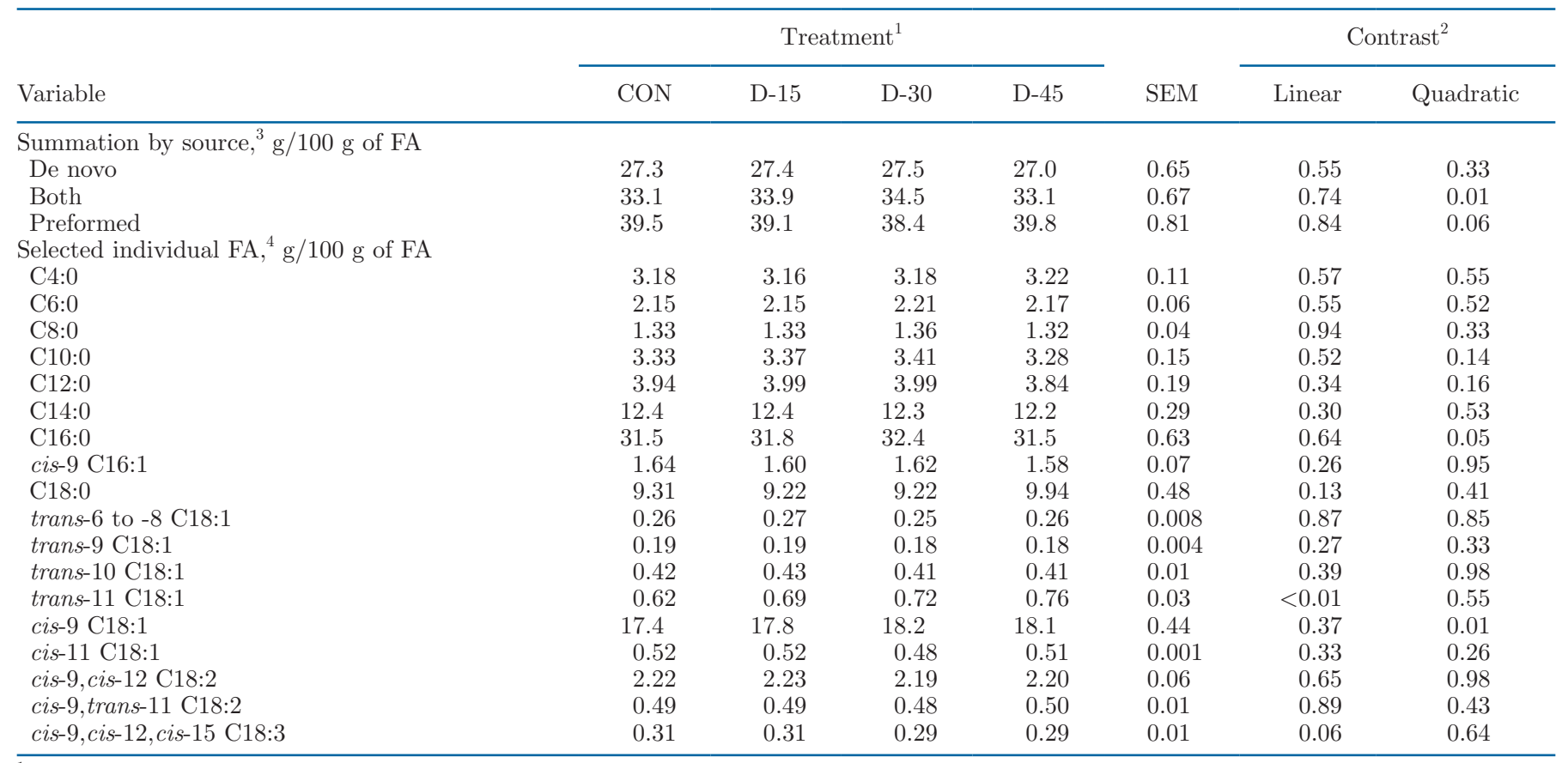

${ }^{1}$ Treatments contained 0 (CON), 15 (D-15), 30 (D-30), or 45 (D-45) g/d of Tween 80 (Sigma-Aldrich, St. Louis, MO) abomasally infused.

${ }^{2}$ Contrasts correspond to the linear and quadratic effects of increasing Tween 80.

${ }^{3}$ De novo FA originate from mammary de novo synthesis ( $<16$ carbons), preformed FA originate from extraction from plasma ( $>16$ carbons), and mixed FA originate from both sources (C16:0 plus cis-9 C16:1).

${ }^{4} \mathrm{~A}$ total of approximately 70 individual FA were quantified and used for calculations (summation by concentrations). Only select FA are reported in the table. 
DMI for UFA has been associated in part by increased secretion of gut peptides related to satiety (i.e., cholecystokinin and GLP-1; Relling and Reynolds, 2007; Bradford et al., 2008).

We did not observe changes in milk yield in response to the exogenous emulsifier infusion. However, both $3.5 \%$ FCM and ECM increased when we infused the exogenous emulsifier up to $30 \mathrm{~g} / \mathrm{d}$. Lee et al. (2019) feeding 2 levels of lysophospholipids to lactating dairy cows reported an increase in milk yield, $4.0 \% \mathrm{FCM}$, and ECM compared with the control diet. Similarly, Shain et al. (1993) reported that feeding soy lecithin to lactating cows increased milk yield and 4.0\% FCM compared with a control diet. Kronfeld (1982) suggested that increased milk yield when FA absorption increases in dairy cows is probably a result of an improved efficiency of milk fat synthesis. Additionally, we did also observe a tendency for greater milk protein yield when we infused the exogenous emulsifier up to $30 \mathrm{~g} / \mathrm{d}$. Similarly, Lee et al. (2019) reported a linear increase in milk protein yield when cows received increased levels of lysophospholipids in the diet. Recently, Brautigan et al. (2017) reported that lysophospholipid supplementation upregulated several genes in intestinal epithelium that are involved in nutrient absorption including AA and increased villus length and width, potentially increasing nutrient absorption in chickens. Although our focus was primary in the effect of emulsifiers on FA digestion, it is possible that infusing the exogenous emulsifier may have improved the absorption of AA or peptides in the gut as observed in nonruminant animals. Therefore, our results are in agreement with previous studies feeding emulsifiers, suggesting a benefit on production performance.

One of our objectives with the emulsifier infusion was to evaluate whether FA digestibility would increase milk fat yield. In our study, we observed that both milk fat content and milk fat yield increased when we infused the exogenous emulsifier up to $30 \mathrm{~g} / \mathrm{d}$. Although Lee et al. (2019) when feeding 2 levels of lysophospholipids to lactating dairy cows did not evaluate FA digestibility, they reported a tendency for an increase in milk fat yield with lysophospholipids compared with the control diet. Interestingly, in our study the increase in milk fat originated from all sources of milk FA (de novo, mixed, and preformed). Similarly, de Souza et al. (2018) reported increased milk fat yield with whole cottonseed compared with a soyhull basal diet due to increases in both de novo and preformed FA. These results are supported by a meta-analysis that highlighted the interdependence between the yields of de novo and 18-carbon FA in milk, proposing that milk lipid synthesis in the mammary gland is dependent upon the simultaneous supply of short/medium-chain FA and long-chain FA
(Glasser et al., 2008). In our study, C16:0 was the major FA increased in milk when we infused the exogenous emulsifier up to $30 \mathrm{~g} / \mathrm{d}$. From de novo FA, we observed increases in the yield of C6:0, C8:0, and C14:0, whereas for preformed FA C18:0 and cis-9 C18:1 yields tended to increase with exogenous emulsifier infusion. The greater increase in the yield of C16:0 may be due to a greater absorption of this FA when the exogenous emulsifier was supplied. A higher preference (8- to 10fold) was observed for C16:0 as a substrate for glycerol3-phosphate acyltransferase, which esterifies FA at sn-1 position to start triglyceride (TAG) synthesis, than for C18:0 or cis-9 C18:1 (Kinsella and Gross, 1973). Recently, Tzompa-Sosa et al. (2014) suggested that an increase in availability of C16:0 for lipid synthesis in mammary epithelial cells may increase the activity of glycerol-3-phosphate acyltransferase in the mammary gland, increasing the proportion of C16:0 acylated at sn-1 at the expense of sn-2. Other FA counterbalance the decrease in the amount of this FA at sn-2. Overall, this hypothesis could explain our finding that milk fat yield increased from all sources of milk FA not only by increasing TAG synthesis, but also potentially by changing the FA inter-positional distribution in the TAG. Taken together, our results indicate that increased FA absorption increases milk fat yield, and it is possible to drive all sources of milk FA, but the mechanisms still need to be determined.

We did not expect changes in glucose concentrations due to the regulatory role of insulin and the glucogenic role of the liver in dairy cattle (Aschenbach et al., 2010). Similarly, we did not expect changes in plasma insulin when we infused the exogenous emulsifier because their benefit is most likely related to lipogenic rather than glucogenic precursors. We observed a slight increase in plasma NEFA when we infused exogenous emulsifier with NEFA concentration increasing up to D-30. Increased concentrations of plasma TAG likely result from increased absorbed FA increasing the supply of TAG-rich lipoproteins available in circulation. Due to incomplete uptake of NEFA after hydrolysis of plasma TAG by lipoprotein lipase, increases in plasma NEFA concentration when more fat is available in circulation are common (Drackley, 1999). The increases that we observed are relatively small compared with NEFA concentrations in early lactation, and the mammary gland would not take up additional NEFA at the concentrations observed in our study (Miller et al., 1991).

\section{CONCLUSIONS}

Abomasal infusion of an exogenous emulsifier in dairy cows resulted in increases in absorption of total, 16-carbon, and 18-carbon FA. Our results suggest that 
limitation in emulsification in the intestine is likely one of the reasons for reduced FA digestibility as the flow of FA to the intestine increases. Additionally, abomasal infusion of an exogenous emulsifier increased milk fat yield due to increasing the yield of all sources of milk FA (de novo, mixed, and preformed). Supplying emulsifier compounds postrumen improved production responses of mid-lactation cows. In our short-term infusion study, most of the digestion and production measurements responded quadratically because the highest dose of exogenous emulsifier $(45 \mathrm{~g} / \mathrm{d})$ decreased DMI and performance.

\section{ACKNOWLEDGMENTS}

We acknowledge C. Preseault, Y. Sun, S. E. Schmidt, K. Wu, K. Spaans, J. L. Spaans, and T.N. Bryant (all in the Department of Animal Science, Michigan State University), the staff of the Michigan State University Dairy Cattle Teaching and Research Center for their assistance in this experiment, and Benemilk US Ltd (Seattle, WA). for partial financial support. Jonas de Souza was supported by a PhD fellowship from Coordenação de Aperfoiçamento de Pessoal de Nivel Superior (CAPES) from the Brazilian Ministry of Education (Brasilia, DF, Brazil). The authors have not stated any conflicts of interest.

\section{REFERENCES}

Allen, M. S. 2000. Effects of diet on short-term regulation of feed intake by lactating dairy cows. J. Dairy Sci. 83:1598-1624. https:// doi.org/10.3168/jds.S0022-0302(00)75030-2.

AOAC. 1990. Official Methods of Analysis. 15th ed. AOAC, Arlington, VA.

Aschenbach, J. R., N. B. Kristensen, S. S. Donkin, H. M. Hammon, and G. B. Penner. 2010. Gluconeogenesis in dairy cows: The secret of making sweet milk from sour dough. IUBMB Life 62:869-877. https://doi.org/10.1002/iub.400.

Bauchart, D. 1993. Lipid absorption and transport in ruminants. J. Dairy Sci. 76:3864-3881. https://doi.org/10.3168/jds.S0022 -0302(93)77728-0.

Boerman, J. P., J. de Souza, and A. L. Lock. 2017. Milk production and nutrient digestibility responses to increasing levels of stearic acid supplementation of dairy cows. J. Dairy Sci. 100:2729-2738. https://doi.org/10.3168/jds.2016-12101.

Boerman, J. P., J. L. Firkins, N. R. St-Pierre, and A. L. Lock. 2015. Intestinal digestibility of long-chain fatty acids in lactating dairy cows: A meta-analysis and meta regression. J. Dairy Sci. 98:88898903. https://doi.org/10.3168/jds.2015-9592.

Bradford, B. J., K. J. Harvatine, and M. S. Allen. 2008. Dietary unsaturated fatty acids increased plasma glucagon-like peptide-1 and cholecystokinin and may decrease premeal ghrelin in lactating dairy cows. J. Dairy Sci. 91:1443-1450. https://doi.org/10.3168/ jds.2007-0670.

Brautigan, D. L., R. Li, E. Kubicka, S. D. Turner, J. S. Garcia, M. L. Weintraut, and E. A. Wong. 2017. Lysolecithin as feed additive enhances collagen expression and villus length in the jejunum of broiler chickens. Poult. Sci. 96:2889-2898. https://doi.org/10 $.3382 / \mathrm{ps} / \mathrm{pex} 078$.

Cochran, R. C., D. C. Adams, J. D. Wallace, and M. L. Galyean. 1986. Predicting the digestibility of different diets with internal markers:
Evaluation of four potential markers. J. Anim. Sci. 63:1476-1483. https://doi.org/10.2527/jas1986.6351476x.

Davis, C. L. 1990. Fats in Animal Feeds. Barnaby Inc., Sycamore, IL.

de Souza, J., C. L. Preseault, and A. L. Lock. 2018. Altering the ratio of dietary palmitic, stearic, and oleic acids in diets with or without whole cottonseed affects nutrient digestibility, energy partitioning, and production responses of dairy cows. J. Dairy Sci. 101:172-185. https://doi.org/10.3168/jds.2017-13460.

de Souza, J., C. Strieder-Barboza, G. A. Contreras, and A. L. Lock. 2019. Effects of timing of palmitic acid supplementation during early lactation on nutrient digestibility, energy balance, and metabolism of dairy cows. J. Dairy Sci. 102:274-287. https://doi.org/ 10.3168/jds.2018-14977.

Doreau, M., and Y. Chilliard. 1997. Digestion and metabolism of dietary fat in farm animals. Br. J. Nutr. 78(Suppl. 1):S15-S35. https://doi.org/10.1079/BJN19970132.

Drackley, J. K. 1999. Biology of dairy cows during the transition period: The final frontier? J. Dairy Sci. 82:2259-2273. https://doi .org/10.3168/jds.S0022-0302(99)75474-3.

Drackley, J. K. 2000. Lipid Metabolism. Pp. 97-119 in Farm Animal Metabolism and Nutrition. J. P. F. D'Mello, ed. CABI Publishing, New York, NY.

Eagle, E., and C. E. Poling. 1956. The oral toxicity and pathology of polyoxyethylene derivatives in rats and hamsters. Food Res. 21:348-361. https://doi.org/10.1111/j.1365-2621.1956.tb16931.x.

Freeman, C. P. 1969. Properties of fatty acids in dispersions of emulsified lipid and bile salt and the significance of these properties in fat absorption in the pig and the sheep. Br. J. Nutr. 23:249-263. https://doi.org/10.1079/BJN19690032.

Glasser, F., A. Ferlay, M. Doreau, P. Schmidely, D. Sauvant, and Y. Chilliard. 2008. Long-chain fatty acid metabolism in dairy cows: A meta-analysis of milk fatty acid yield in relation to duodenal flows and de novo synthesis. J. Dairy Sci. 91:2771-2785. https://doi.org/ 10.3168/jds.2007-0383.

Goering, H. K., and P. J. Van Soest. 1970. Forage Fiber Analysis (Apparatus, Reagents, Procedures, and Some Applications). Agric. Handbook No. 379. USDA-ARS, Washington, DC.

Harrison, F. A., and W. M. F. Leat. 1972. Absorption of palmitic, stearic, and oleic acids in the sheep in the presence or absence of bile and/or pancreatic juice. J. Physiol. 225:565-576. https://doi .org/10.1113/jphysiol.1972.sp009956.

Jenkins, T. C., and N. Fotouhi. 1990. Effects of lecithin and corn oil on site of digestion, ruminal fermentation and microbial protein synthesis in sheep. J. Anim. Sci. 68:460-466. https://doi.org/10 $.2527 / 1990.682460 \mathrm{x}$.

Kamande, G. M., J. Baah, K.-J. Cheng, T. A. McAllister, and J. A. Shelford. 2000. Effects of Tween 60 and Tween 80 on protease activity, thiol group reactivity, protein adsorption, and cellulose degradation by rumen microbial enzymes. J. Dairy Sci. 83:536-542. https://doi.org/10.3168/jds.S0022-0302(00)74913-7.

Kinsella, J. E., and M. Gross. 1973. Palmitic acid and initiation of mammary glyceride synthesis via phosphatidic acid. Biochim. Biophys. Acta 316:109-113. https://doi.org/10.1016/0005-2760(73)90172-0.

Kronfeld, D. S. 1982. Major metabolic determinants of milk volume, mammary efficiency. and spontaneous ketosis in dairy cows. J. Dairy Sci. 65:2204-2212. https://doi.org/10.3168/jds.S0022 $-0302(82) 82483-1$

Lee, C., D. L. Morris, J. E. Copelin, J. M. Hettick, and I. H. Kwon. 2019. Effects of lysophospholipids on short-term production, nitrogen utilization, and rumen fermentation and bacterial population in lactating dairy cows. J. Dairy Sci. 102:3110-3120. https://doi .org/10.3168/jds.2018-15777.

Lee, S. S., B. H. Ahn, H. S. Kim, C. H. Kim, K.-J. Cheng, and J. K. Ha. 2003. Effects of non-ionic surfactants on enzyme distributions of rumen contents, anaerobic growth of rumen microbes, rumen fermentation characteristics and performance of lactating cows. Asian-australas. J. Anim. Sci. 16:104-115. https://doi.org/ 10.5713/ajas.2003.104.

Lock, A. L., K. J. Harvatine, J. K. Drackley, and D. E. Bauman. 2006. Concepts in fat and fatty acid digestion in ruminants. Pages 85-100 in Proc. Intermountain Nutr. Conf. 
Lock, A. L., C. L. Preseault, J. E. Rico, K. E. DeLand, and M. S. Allen. 2013. Feeding a C16:0-enriched fat supplement increased the yield of milk fat and improved conversion of feed to milk. J. Dairy Sci. 96:6650-6659. https://doi.org/10.3168/jds.2013-6892.

Lock, A. L., C. Tyburczy, D. A. Dwyer, K. J. Harvatine, F. Destaillats, Z. Mouloungui, L. Candy, and D. E. Bauman. 2007. Trans-10 octadecenoic acid does not reduce milk fat synthesis in dairy cows. J. Nutr. 137:71-76. https://doi.org/10.1093/jn/137.1.71.

Marszall, L. 1973. Toxicological aspects of the use of Span and Tween products in pharmaceuticals, cosmetics, and the food industry. Bromatol. Chem. Toksykol. 6:187-195.

McAllister, T. A., K. Stanford, H. D. Bae, R. J. Treacher, A. N. Hristov, J. Baah, J. A. Shelford, and K.-J. Cheng. 2000. Effect of a surfactant and exogenous enzymes on digestibility of feed and on growth performance and carcass traits of lambs. Can. J. Anim. Sci. 80:35-44. https://doi.org/10.4141/A99-053.

Miller, P. S., B. L. Reis, C. C. Calvert, E. J. DePeters, and R. L. Baldwin. 1991. Relationship of early lactation and bovine somatotropin on nutrient uptake by cow mammary gland. J. Dairy Sci. 74:38003806. https://doi.org/10.3168/jds.S0022-0302(91)78572-X.

Moore, H., and W. W. Christie. 1984. Digestion, absorption and transport of fats in ruminant animals. Page 123 in Fats in Animal Nutrition. J. Wiseman, ed. Butterworths, London, UK.

NRC. 2001. Nutritional Requirements of Dairy Cattle. 7th rev. ed. Natl. Acad. Sci., Washington, DC.

Ockner, R. K., J. P. Pittman, and J. L. Yager. 1972. Differences in the intestinal absorption of saturated and unsaturated long chain fatty acids. Gastroenterology 62:981-992. https://doi.org/10.1016/ S0016-5085(72)80115-X.

Palmquist, D. L., and T. C. Jenkins. 1980. Fat in lactation rations. J. Dairy Sci. 63:1-14. https://doi.org/10.3168/jds.S0022 -0302(80)82881-5.

Piantoni, P., A. L. Lock, and M. S. Allen. 2013. Palmitic acid increased yields of milk and milk fat and nutrient digestibility across production level of lactating cows. J. Dairy Sci. 96:7143-7154. https://doi .org/10.3168/jds.2013-6680.
Relling, A. E., and C. K. Reynolds. 2007. Feeding rumen-inert fats differing in their degree of saturation decreases intake and increases plasma concentrations of gut peptides in lactating dairy cows. J. Dairy Sci. 90:1506-1515. https://doi.org/10.3168/jds.S0022 -0302(07)71636-3.

Rico, J. E., J. de Souza, M. S. Allen, and A. L. Lock. 2017. Nutrient digestibility and milk production responses to increasing levels of palmitic acid supplementation vary in cows receiving diets with or without whole cottonseed. J. Anim. Sci. 95:436-446. https://doi .org/10.2527/jas.2016.1089.

Shain, D. H., M. H. Sindt, R. J. Grant, T. J. Klopfenstein, and R. A. Stock. 1993. Effect of soybean hull:soy lecithin:soapstock mixture on ruminal digestion and performance of growing beef calves and lactating dairy cattle. J. Anim. Sci. 71:1266-1275. https://doi.org/ 10.2527/1993.7151266x.

Tzompa-Sosa, D. A., G. A. van Aken, A. C. M. van Hooijdonk, and H. J. F. van Valenberg. 2014. Influence of C16:0 and long-chain saturated fatty acids on normal variation of bovine milk fat triacylglycerol structure. J. Dairy Sci. 97:4542-4551. https://doi.org/ 10.3168/jds.2014-7937.

Upadhaya, S. D., J. W. Park, J. H. Park, and I. H. Kim. 2017. Efficacy of 1,3-diacylglycerol as a fat emulsifier in low-density diet for broilers. Poult. Sci. 96:1672-1678. https://doi.org/10.3382/ps/pew425.

Weiss, W. P., J. M. Pinos-Rodríguez, and D. J. Wyatt. 2011. The value of different fat supplements as sources of digestible energy for lactating dairy cows. J. Dairy Sci. 94:931-939. https://doi.org/ $10.3168 /$ jds.2010-3745.

Wildman, E. E., G. M. Jones, P. E. Wagner, and R. L. Boman. 1982. A dairy cow body condition scoring system and its relationship to selected production characteristics. J. Dairy Sci. 65:495-501. https://doi.org/10.3168/jds.S0022-0302(82)82223-6.

Zhao, P. Y., H. L. Li, M. M. Hossain, and I. H. Kim. 2015. Effect of emulsifier (lysophospholipids) on growth performance, nutrient digestibility and blood profile in weanling pigs. Anim. Feed Sci. Technol. 207:190-195. https://doi.org/10.1016/j.anifeedsci.2015 .06 .007 . 